\title{
Enablers of Sustainability in Agriculture Supply Chains: An ISM approach
}

\author{
Sandeep Singh \\ Senior Research Associate, O P Jindal Global University, Haryana, India-131001
}

\begin{abstract}
The purpose of this study is to identify the key enablers of triple bottom line in agriculture supply chains with focus on Indian agriculture sector, and to analyze their interrelationship and level of influence on sustainability. Literature review and experts' brainstorming is used to identify the list of enablers corresponding to the three dimensions of sustainability. Diagraph showing structured hierarchy among them is developed using ISM approach. The influence of each enabler was calculated using MICMAC analysis. The experts from the sugar industry as well as the farmers (living at bottom of pyramid of agriculture sector) were involved in identifying enablers and in pair wise comparison to elucidate the contextual relationship between enablers of the dimensions. The paper shows interconnection between the dimensions of triple bottom line of sustainability and identifies the key enablers for each dimension. This research shows that there exist a set of enablers having high driving power can significantly influence the sustainable supply chain practices in bottom of pyramid of agriculture sector. These enablers are of strategic importance and if neglected while policy framing, might result into the failure of sustainability drive of whole agriculture supply chain. Those enablers having high dependence and low driving power are the resultant action of the driving enablers. This paper also consolidates the fragmented knowledge of sustainable supply chain management in agriculture sector and suggests a pathway to policy makers and practitioners for framing sustainability policies. The precedence diagraph and MICMAC analysis provides a useful tool for practitioners to distinguish between the high driving and low driving enablers of TBL and their interrelations in context of agriculture supply chain. This will help managers to focus on the significant areas while taking operational or strategic decisions for sustainable agriculture supply chain. It also gives path to improve the livelihood of people living in the bottom of pyramids in agriculture sector. The findings can also be propagating in other bottom of pyramid markets for sustainability goals.

Keywords: Sustainability, Agriculture, ISM, MICMAC, Triple bottom line, Supply Chain Management, etc.
\end{abstract}

